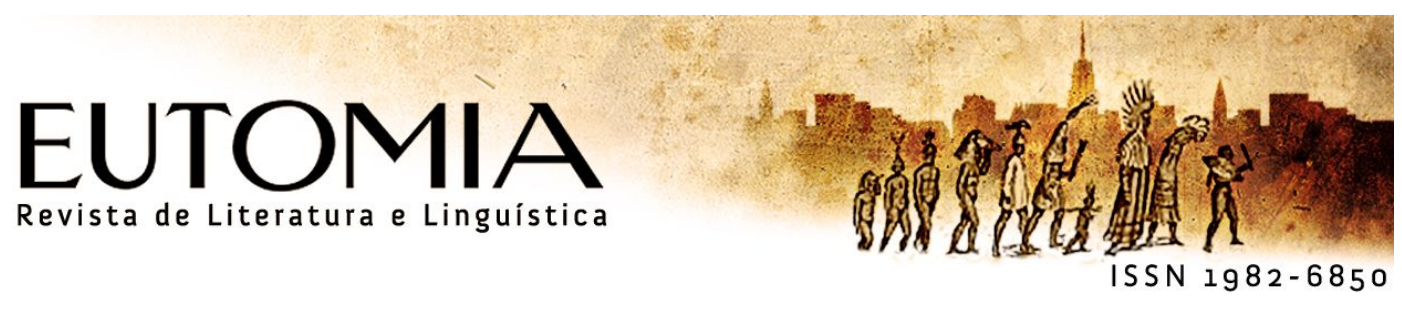

\title{
Interacionismo Sociodiscursivo e Trabalho Colaborativo: Possibilidades de Formação Continuada
}

\author{
Mariolinda Rosa Romera Ferrazi (UFGD) \\ Adair Vieira Gonçalves ii(UFGD)
}

\begin{abstract}
Resumo: Neste artigo, objetiva-se defender o Interacionismo Sociodiscursivo como uma concepção teórica e uma vertente didática (BRONCKART, 2007; DOLZ, NOVERRAZ, SCHNEUWLY, 2004) integrante do currículo de cursos de formação continuada de professores articulado ao trabalho colaborativo. Inicialmente, apresenta-se o contexto de uma pesquisa que adotou esta concepção teórico-metodológica; em seguida, relatam-se aspectos da formação desenvolvida, na qual professores efetuaram a construção de modelo didático e de sequência didática. Para se avaliar as concepções docentes, prévias e/ou aprimoradas, sobre o aporte teórico, foram aplicados dois questionários: o primeiro (com og questões e respondido por 13 professores) no início, e o segundo (com 10 questões e respondido por og professores) no final do curso, cuja carga horária total foi de 140h, sendo $12 \mathrm{~h}$ horas destinadas para modelização de gênero e zoh à planificação da sequência didática. Ademais, a geração dos dados foi feita também por meio de material audiovisual, do/no qual se evidenciam as reflexões docentes sobre as implicações desta concepção no fazer pedagógico do professor de língua.
\end{abstract}

Palavras-chave: interacionismo sociodiscursivo; formação continuada de professores; trabalho colaborativo.

\begin{abstract}
This paper aims to defend the Sociodiscursive Interactionism as a theoretical conception and a didactic aspect (BRONCKART, 2007; DOLZ, NOVERRAZ, SCHNEUWLY, 2004) embedded in the curriculum for the teachers of the continuing education course together with the collaborative work. Firstly, this work will introduce the context of a research which has adopted the theoretical and methodological conception; secondly, it will report aspects of the developed education in which the teachers have carried out the construction of the didactic model and didactic sequence. To evaluate the previous and/or perfected conceptions of the teachers about the theoretical contribution, two questionnaires were applied: the first, which included og questions and was answered by 13 of the teachers, was made in the beginning of the course, and the second, which included 10 questions and was answered by og teachers, was made by the end of the course. The course had a total of 140 hours, of which 12 hours were destined to genre modeling and 30 hours destined to didactic sequence planning. Besides all the data analysis, there was also an audiovisual material, which clarifies the reflections of the teachers about all the implications of this conception to the Language teacher Pedagogy.
\end{abstract}

Keywords: sociodiscursive interactionism; teachers' continuing education; collaborative work. 


\section{Contexto da pesquisa}

Este artigo é um recorte ${ }^{1}$ de uma investigação mais ampla intitulada "Formação Continuada de professores e a transposição didática externa dos gêneros artigo de opinião e notícia", resultante de uma pesquisa que pretendeu fomentar a formação continuada de professores para a efetivação e avaliação do fazer pedagógico à luz da didática de línguas da equipe de Genebra.

A pesquisa-ação, de cunho qualitativo-interpretativista e de natureza colaborativa, foi desenvolvida em três etapas de transposição didática externa e interna²: 1) (TP1) Transposição Didática Externa - formação continuada de professores; 2) (TP2) Transposição Didática Externa - mediação de professores para modelização de gêneros e planificação de sequências didáticas (doravante, $\mathrm{SD})^{3}$; e 3) ( $\left.\mathrm{TP}_{3}\right)$ Transposição Didática Interna desenvolvimento das SD. A quarta etapa da pesquisa consistiu na análise dos resultados do processo efetivado fora e dentro da sala de aula.

Na TP1 realizou-se a "Formação Continuada para Professores de Língua Portuguesa das Escolas das Redes Municipal e Estadual de Ensino de Dourados/MS: O Interacionismo Sociodiscursivo - das bases epistemológicas à práxis pedagógica", cuja carga horária foi de

\footnotetext{
${ }^{1}$ Este artigo está relacionado a outros artigos e capítulos de livros, aos quais se remete o leitor para conhecimento mais detalhado da pesquisa desenvolvida, entre eles: "Formação continuada de professores: o interacionismo sociodiscursivo - das bases epistemológicas à práxis pedagógica", publicado na Revista Raído (Dourados, MS, v. 6, n. 11, jan./jun. 2012); "Sequência didática: ferramenta de aprimoramento da prática pedagógica e de desenvolvimento dos saberes discentes", publicado no livro Experiências com sequências didáticas de gêneros textuais" (Pontes Editora, 2014); e "Sequências Didáticas como instrumento potencial da formação docente reflexiva", no prelo, pela Revista Delta.

${ }^{2}$ As diversas aporias do conceito de transposição didática, tratadas em disciplinas correlatas, não serão discutidas e problematizadas neste trabalho. Destaca-se, no entanto, que o conceito de transposição didática nasce no trabalho de um sociólogo (VERRET, 1975), migra para o campo da Didática da Matemática a partir dos estudos de Chevallard (1985) e, neste trabalho, adota-se o conceito desenvolvido por Machado e Cristóvão (2006), particularmente quando as autoras tratam dos níveis de transposição, a saber: nível 1 - o conhecimento científico que se transforma em conhecimento a ser ensinado; nível 2 - o conhecimento a ser ensinado que se transforma em conhecimento efetivamente ensinado; nivel 3 - conhecimento efetivamente ensinado que se transforma em conhecimento efetivamente aprendido. $\mathrm{E}$ os termos transposição didática externa e interna são recuperados em Barros (2012).

3 Vale esclarecer que a TP2 teve início durante a $T P_{1}$, ou seja, todos os professores participantes da formação modelizaram gêneros e planificaram SD. No entanto, dois professores foram convidados para colaborarcom a pesquisa e receberam atendimento particularizado para o desenvolvimento das atividades e, posteriormente, aplicação das SD em suas salas de aula, a saber, uma turma de $3^{\circ}$ ano do ensino médio e uma turma de $9^{\circ}$ ano do ensino fundamental, ambas de duas escolas públicas da Rede Estadual de Ensino de Mato Grosso do Sul, na cidade de Dourados/MS.
} 
140 horas $^{4}$, nas quais foram realizadas atividades diversas, como estudos individuais e coletivos sobre o aporte teórico-metodológico do ISD, modelização de gênero, planificação de SD, aplicação das SD, e, finalmente, socialização das práticas desenvolvidas em sala de aula, momento marcado por reflexões sobre o fazer pedagógico e o currículo de língua portuguesa.

Nesta pesquisa, defenderam-se as concepções teórico-metodológicas do ISD como "componentes curriculares" para a formação (inicial e continuada) reflexiva de professores, considerando que tal abordagem, em sua vertente didática, investiga a materialização das atividades de linguagem ${ }^{5}$ em gêneros textuais, a partir do reconhecimento das práticas sociais, das práticas de linguagem e das representações que enunciadores ${ }^{6}$ fazem dos contextos de produção7 em que estão inseridos. Por exemplo, os professores precisaram (re) conhecer os fundamentos teóricos básicos do Interacionismo Sociodiscursivo (ISD, daqui para frente), compreender, sobretudo, aspectos da didática a respeito da modelização de gêneros, para depreender-lhes os objetos ensináveis e, em seguida, planificar a SD. Após esse percurso, o trabalho com gêneros textuais (BRONCKART, 2007), à luz do ISD, pôde ser efetivado. É o que tentamos mostrar nas seções seguintes.

\section{A formação continuada e a concepção de gêneros dos professores}

Nesta seção, além de refletir brevemente sobre o processo colaborativo de formação continuada e a possibilidade de reflexividade dele decorrente, apresentam-se o cronograma do curso e as representações teórico-metodológicas a respeito de gêneros textuais/discursivos dos docentes implicados nesta pesquisa.

\footnotetext{
4 Todas as aulas foram gravadas em vídeos e os encontros de mediação dos professores, gravados em áudio. Além do material fonográfico e audiovisual, constituíram o corpus da pesquisa, dois questionários aplicados durante a formação de professores e as produções (inicial e final) dos alunos.

${ }^{5}$ As atividades de linguagem são compreendidas como configurações sociais organizadoras e reguladoras da interação entre os indivíduos e o meio. Elas são constituídas por ações de linguagem, isto é, por condutas linguísticas motivadas e realizadas em um contexto de produção particular para o indivíduo. Portanto, a atividade está para o agir coletivo; a ação está para o agir individual.

${ }^{6}$ No ISD, "a noção de enunciador designa as propriedades sociosubjetivas do autor, do modo como podem ser apreendidas por uma análise externa de sua situação de ação. [...] designa, na verdade, um construto teórico, uma instância puramente formal, a partir da qual são distribuídas as vozes que se expressam em um texto." (BRONCKART, 2007, p. 95).

7 O Contexto de produção é o "conjunto de parâmetros que podem exercer influência sobre a forma como um texto é organizado" (BRONCKART, 2007, p. 93). É composto por elementos oriundos do mundo real (situados fisicamente no tempo e no espaço) e/ou do mundo psicossocial (situados virtual e sociodiscursivamente), no ISD, respectivamente, mundo físico e mundo subjetivo/social (ou sociossubjetivo).
} 
As inovações, a que se referem as pesquisas mais recentes (décadas finais do século XX e primeira década do século XXI) no campo da LA, dizem respeito à articulação entre os conhecimentos de diversas teorias e as práticas efetivadas em sala de aula, fundamentando a reflexividade e a colaboração.

A definição de colaboração [...] não implica em aceitação do novo e em refutação do velho. Significa refletir sobre ambos, o novo e o velho, por meio de questionamentos, conflitos e ações. A ação colaborativa, segundo Magalhães (2002a), revela contextos em que os participantes constroem sentidos, questionam suas representações e valores e retomam sua ação, problematizando suas escolhas. Essas ações são compartilhadas, muitas vezes, entre professor e pesquisador, os quais não têm, necessariamente, o mesmo papel. Os diferentes papéis podem inclusive marcar as diferenças de poder que podem se estabelecer na relação, dada pelo lugar institucional que cada um ocupa e que também podem ser questionados. É nessa interação com o outro que se constitui o profissional auto-reflexivo. Para a autora, a partir dos possíveis conflitos na relação entre, por exemplo, professores e assessores, a compreensão das práticas discursivas da sala de aula é negociada. Nesse sentido, as próprias negociações são tidas como ferramentas para a formação contínua do professor, como proposto por Schneuwly (1994). Assim com essa ferramenta, repensam-se os papéis do professor, dos alunos e do material didático, e transformações começam a ocorrer. (CRISTOVÃO, 2009 [2004], p. 181-182)

É na diversidade de práticas, de opiniões, e na socialização delas que acontece a colaboração, a formação reflexiva coletiva. O conceito de colaboração pressupõe coautoria. Professor-formador/professor-cursista ou professores-cursistas entre si, produzindo novos olhares para a educação e novas perspectivas de ação. "O processo reflexivo não acontece sozinho. É, na verdade, um trabalho ativo, consciente que pressupõe esforço, vontade e que tem lugar quando condições são criadas para isso" (CELANI, 2010 [2002], p. 26). Em seu aspecto prático, a colaboração favorece a produção, como nesta pesquisa em que os professores produziram SD. No âmbito da pesquisa colaborativa, os envolvidos nesse processo tornam-se críticos/questionadores (FREIRE, 1997, 2002; GIROUX, 1997; KINCHELOE, 1997; MAGALHÃES, 2009 [2004] CELANI,2010 [ 2002] ) da própria ação e, amplamente, da situação educacional. Tornam-se coparticipantes de uma pesquisa-ação, posto que a colaboração é 
uma tarefa de construção conjunta, através da qual tanto o coordenador ${ }^{8}$ quanto o professor buscam oportunidades iguais para apresentar e discutir criticamente valores, significações, teorias de ensino e aprendizagem numa tentativa de entender, questionar, explicar, interpretar e expandir os assuntos envolvidos no contexto, na realidade e na prática encontrados na sala de aula. Por esse motivo, opiniões diferentes e conflitos são elementos associados ao processo de construção do conhecimento. (ROMERO, 2009 [2004], p. 137)

O estabelecimento do diálogo, da troca, fortalece os professores e imprime um processo de autorreflexão. A atividade coletiva provoca um sentimento de autoavaliação e autovalorização, pois o professor, ao perceber-se como o e no outro, sente-se "amparado" para continuar e criar. Além do mais, os atores estabelecem um pacto (virtual) social de estudo, aprendizagem e desenvolvimento, podendo, inclusive avaliar sua formação, as práticas realizadas em curso e na escola e as políticas da educação.

A pesquisa desenvolvida considerava que, se, por um lado, a formação continuada de professores pode fazer persistir e/ou ratificar as agruras da didatização do conhecimento, por outro, ela própria é caminho para reversão de rupturas na transposição didática e de aprimoramento do processo ensino-aprendizagem, a iniciar pela compreensão adequada dos referenciais teórico-metodológicos para o ensino da Língua Portuguesa. Sendo assim, um dos primeiros pontos observados na mediação formativa foi a seleção dos saberes científicos a serem transformados em saberes a ensinar. Assim, delinearam-se as razões da formação de professores e pensou-se em seu formato, cujo planejamento dos encontros presenciais foi assim organizado:

\begin{tabular}{|l|l|}
\hline Encontro & Objeto de estudo/Atividade \\
\hline 1 & $\begin{array}{l}\text { Abertura do curso; Informes gerais: objetivos do curso, formato } \\
\text { (semipresencial), relação entre a formação continuada e a pesquisa, } \\
\text { cronograma, carga horária e certificação. }\end{array}$ \\
\hline 2 & $\begin{array}{l}\text { ISD: fundamentos teóricos - práticas sociais, práticas de linguagem, } \\
\text { interação. Aspectos didáticos: capacidades de linguagem, introdução aos } \\
\text { gêneros textuais. Diagnóstico sobre o ISD e seus desmembramentos. }\end{array}$ \\
\hline 3 & $\begin{array}{l}\text { Práticas sociais, práticas de linguagem, esferas de comunicação, contexto de } \\
\text { produção e gêneros textuais; Gêneros textuais - infraestrutura e contexto de } \\
\text { produção, produção de texto. }\end{array}$ \\
\hline 4 & $\begin{array}{l}\text { Atividade a distância: estudo de texto e seleção de textos no gênero a ser } \\
\text { didatizado. }\end{array}$ \\
\hline
\end{tabular}

\footnotetext{
${ }^{8}$ Em processos de formação como o da pesquisa em relato, o professor-formador.
} 


\begin{tabular}{|l|l|}
\hline 5 & Gêneros Textuais - sequências tipológicas e tipos de discurso. \\
\hline 6 & Fundamentos metodológicos - modelo didático, lista de constatação, SD. \\
\hline 7 & Construção em grupo de um modelo didático - gênero artigo de opinião \\
\hline 8 & $\begin{array}{l}\text { Construção de modelos didáticos nos gêneros escolhidos pelos professores e } \\
\text { de SD. }\end{array}$ \\
\hline 9 & $\begin{array}{l}\text { Recapitulação do tema SD e desenvolvimento da SD - Resumo; Trabalhando } \\
\text { com a gramática: exercícios de gramática funcional. }\end{array}$ \\
\hline 10 & $\begin{array}{l}\text { Conclusão da SD sobre Resumo; Lista de controle; Exercício de Revisão de } \\
\text { texto. }\end{array}$ \\
\hline 11 & Construção de uma SD (etapa a distância da formação; mediação por e-mail). \\
\hline 12 & $\begin{array}{l}\text { Apresentação dos modelos didáticos e sequências didáticas construídas } \\
\text { (socialização do material). }\end{array}$ \\
\hline 13 & Etapa de aplicação da SD elaborada. \\
\hline 14 & $\begin{array}{l}\text { Socialização das experiências de aplicação das SD e questionamentos. } \\
\text { Socialização das experiências de aplicação das SD e questionamentos; }\end{array}$ \\
\hline 15 & Curso; Encerramento. \\
\hline
\end{tabular}

Quadro 1: Cronograma da Formação

Logo no início do curso, foi feito o diagnóstico do conhecimento dos professorescursistas sobre os temas da formação. Apenas quatro professores disseram ter tido contato com os aspectos teórico-metodológicos do ISD. Uma tinha a titulação de mestre. Outro tinha feito uma disciplina como aluno especial no curso de Mestrado em Letras da UFGD e duas eram recém-formadas. Essa ação possibilitou redimensionar o programa da formação, (re)definindo o caminho a ser seguido.

Com a finalidade de introduzir as discussões sobre práticas sociais, práticas de linguagem, esferas de comunicação, contextos de produção e gêneros textuais, já que as primeiras configuram-se como espaços amplos de atividades de linguagem, determinantes das segundas, por sua vez, resultantes em ações de linguagem, que, enfim, se efetivam nos terceiros (BRONCKART, 2007), a atividade central do encontro foi assistir ao filme Big Fish (Peixe Grande e suas histórias maravilhosas, em português), de Tim Burton. As questões abaixo nortearam o olhar dos educadores.

1- Que práticas sociais de linguagem estão presentes no filme?

2- Os contos/causos contados pelo pai são adequados às situações sóciocomunicativas? Justifique sua resposta, exemplificando com situações (in)adequadas, conforme sua avaliação. 
3- Que reações um texto/discurso inadequado ao contexto pode provocar? Qual a reação provocada no filme?

As discussões geraram indagações a respeito de como os professores desenvolviam suas práticas de ensino com gêneros textuais e/ou como orientavam as produções de texto, posteriormente investigadas na avaliação do curso. A terceira pergunta da avaliação foi: "Em sua prática pedagógica, você já desenvolvia atividades com gênero textuais? Relate como era sua prática." A análise das respostas permitiu a seguinte sistematização:

- quatro professores afirmaram trabalhar com gêneros textuais, conforme as atividades apresentadas no livro didático;

- um professor disse não trabalhar com gêneros textuais e que mantém a terminologia dos tipos de texto (narração, descrição, dissertação);

- outro professor limitou sua resposta a um "não", sem explicações;

- seis professores ${ }^{9}$ afirmaram trabalhar com gêneros textuais, mas nenhum deles fez referência ao desenvolvimento de uma SD tampouco da orientação da produção pela indicação de um contexto de produção ${ }^{10}$.

A respeito dos gêneros textuais em si, uma observação feita foi a de que, apesar de os professores não titubearem na nomeação dos gêneros (eles distinguem, perfeitamente, os gêneros de circulação na esfera escolar: crônicas, lendas, fábulas, artigo de opinião, editorial etc.), insistem na nomeação dos gêneros menos comuns ${ }^{11}$, ou até dos gêneros primários. A preocupação dos professores era "que gênero é esse?"; o que provocou as seguintes explicações: a distinção do gênero perpassa pelas situações de comunicação, pelo suporte, pela finalidade, por aspectos enunciativos; além disso, os gêneros se "transformam" ao longo da história ou sofrem hibridização, por conseguinte, são esses os aspectos a serem observados no desenvolvimento de atividades de ensino dos gêneros textuais, para que os alunos possam "mover-se" adequadamente em diferentes situações sociocomunicativas e/ou efetivar competentemente diversas ações de linguagem

\footnotetext{
9 Alguns desses professores disseram, inclusive, já ter aplicado uma das SD da Olimpíada de Língua Portuguesa. Apesar disso, não relataram o uso de consignas referentes ao contexto de produção.

${ }_{10}$ Tais respostas comprovam que aos alunos não é oferecido um contexto de produção e que há um tradicionalismo de conteúdo e de práticas de ensino.

${ }^{11}$ Chamamos de gêneros menos comuns os textos que saem de sua função social (ou cristalizada); por exemplo, uma receita para fazer um vaso de planta com sucata, uma bula indicativa do "remédio da felicidade", "o que é o que?" etc.
} 
(SCHNEUWLY; DOLZ, 2004). O ensino da linguagem deve estar voltado para as bases enunciativas de uma produção.

A esse respeito, destacam-se duas falas de professores.

1- "Interessante que, quanto mais você fala de gêneros textuais, de tipos de textos, aliás, sequências tipológicas, e tudo isso aí, mais eu tenho certeza de que eu não sei nada de português e de tipos de textos."

2- "Essa proposta é muito boa. Ela detalha o texto bem detalhadinho. Mas pra nós professores, quando nós vamos ter tempo para estudar tudo isso e preparar uma aula assim? Você deve ter passado horas estudando e preparando material. E nós? Que tempo temos, trabalhando 40h? Por isso que a gente fica com o livro didático porque já vem tudo prontinho. É só ir lá na aula e aplicar".

Os respectivos comentários da professora ministrante foram:

1- Professora, você sabe sim tudo isso. Inclusive a língua portuguesa é a sua língua. Acontece que nós fomos ensinados com os tipos textuais - narrativo, descritivo e dissertativo - que não davam conta de tudo isso. Os estudos mais modernos ampliam a forma de analisar o texto porque consideram a interação. Eles mostram que nós falamos e escrevemos de acordo com nossas necessidades de comunicação e com a situação de comunicação em que estamos.

2- Professora, o que é difícil, na verdade, não é a teoria nova que estamos estudando. É preciso uma reforma política na e para a educação, a começar pela LDB e nosso $\mathrm{PCCR}^{12}$. Você não acha? (não houve outra resposta - apenas troca de olhares que sinalizaram a resposta).

A primeira fala, mais especificamente, provocou a investigação de como os professores em formação concebiam os gêneros textuais. Eles foram instados a desenvolver o conceito de gêneros textuais. As respostas foram sistematizadas no seguinte quadro:

12 "PCCR", forma como é chamada a Lei complementar n 118, de 31/12/2007, que dispõe sobre o Plano de Cargos, Carreira e Remuneração do Profissional da Educação Municipal de Dourados. 


\begin{tabular}{|c|c|c|}
\hline $\begin{array}{l}\text { Categoria de } \\
\text { definição }\end{array}$ & Fragmentos de algumas respostas & Análise \\
\hline $\begin{array}{l}\text { Tipo de texto } \\
\left(2^{13}\right)\end{array}$ & $\begin{array}{l}\text { "Os gêneros são as várias } \\
\text { modalidades dos diversos tipos de } \\
\text { texto" }\left(\mathrm{P}_{29}\right)^{14} ; \\
\text { "[...] são tipos específicos de texto" } \\
(\mathrm{P} 49) \text {. }\end{array}$ & $\begin{array}{l}\text { A resposta demonstra um } \\
\text { tradicionalismo conceitual. Está } \\
\text { enraizada a definição (e a } \\
\text { prática) com tipos de texto. }\end{array}$ \\
\hline $\begin{array}{l}\text { Variedade de } \\
\text { gêneros (2) }\end{array}$ & $\begin{array}{l}\text { "São várias formas de apresentação } \\
\text { de um texto }[. . .] \text { podem ser quase } \\
\text { infinitos" }\left(\mathrm{P}_{41}\right) ; \\
\text { "[...] diferentes maneiras de textos, } \\
\text { orais ou escritos" }\left(\mathrm{P}_{5}\right) \text {. }\end{array}$ & $\begin{array}{l}\text { Para a formulação do conceito } \\
\text { de gênero, foram observados } \\
\text { os diversos gêneros existentes. } \\
\text { Parece não haver uma reflexão } \\
\text { de que os gêneros variam } \\
\text { porque mudam também as } \\
\text { situações comunicativas. }\end{array}$ \\
\hline $\begin{array}{l}\text { Constructo } \\
\text { Social (9) }\end{array}$ & 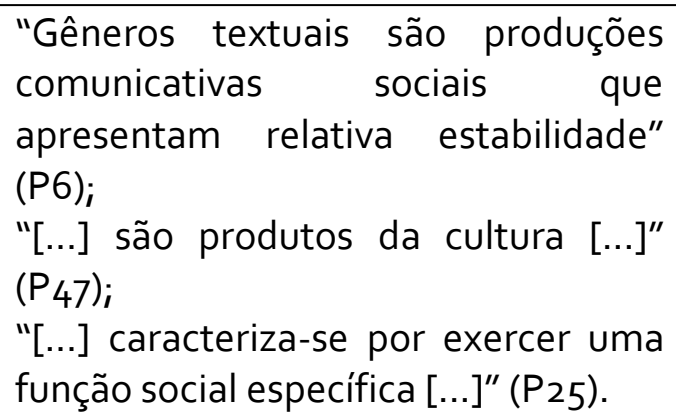 & $\begin{array}{l}\text { As respostas apontam o caráter } \\
\text { sociocomunicativo dos } \\
\text { gêneros, ou seja, o gênero é } \\
\text { entendido como enunciado } \\
\text { estável com função específica. }\end{array}$ \\
\hline
\end{tabular}

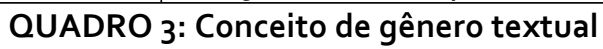

Considerando as respostas dadas, infere-se que a maioria dos professores parece ter assimilado a definição de gêneros textuais, mas não que, exatamente, tinha essas concepções antes da formação.

\section{O processo de construção do modelo didático e aspectos relacionados à didatização}

Nesta seção, apresentamos aspectos teórico-metodológicos relativos ao contexto de produção, aspectos relacionados às tipologias textuais e sua relação com os gêneros

\footnotetext{
${ }^{13}$ Os números entre parênteses referem-se à quantidade de resposta nas "categorias" correspondentes.

${ }^{14}$ Destaca-se que esta avaliação foi escrita. Para preservar a identidade dos cursistas, as avaliações foram numeradas. Por isso, utilizam-se duas formas de citação das falas dos professores-cursistas: a primeira, apenas a fala entre aspas, foi um comentário de um professor durante o curso, registrado pela professoraformadora em seu "diário de bordo". A segunda, a letra "P" - referente a professor - e um número - referente ao número da avaliação, entre parênteses, é a resposta (ou fragmento da resposta) dada a uma pergunta do questionário, como aparece no OUADRO 3.
} 
textuais, além dos princípios de legitimidade, pertinência e solidarização circundantes da construção do Modelo Didático e da planificação da SD.

Em um dos encontros, os professores, em grupo, produziram textos em diversos gêneros, orientados por contextos de produção (Cf. OUADRO 2), que tomavam como tema o filme assistido.

\begin{tabular}{|c|c|}
\hline Gênero & Contexto de Produção \\
\hline $\begin{array}{l}\text { Artigo } \\
\text { Opinião }\end{array}$ & $\begin{array}{l}\text { Você é professor de séries inicias e, ao longo de sua prática } \\
\text { pedagógica, tem desenvolvido atividades de contação de história. } \\
\text { Pelos excelentes resultados obtidos em relação ao aprimoramento da } \\
\text { linguagem verbal das crianças, o estímulo à imaginação, o } \\
\text { enriquecimento vocabular, o favorecimento da reflexão crítica e a } \\
\text { promoção da interação social, você decidiu escrever um artigo de } \\
\text { opinião, a ser veiculado no Caderno B do Jornal Folha Douradense, } \\
\text { argumentando sobre "a importância da contação de história". Na sua } \\
\text { argumentação, inclusive, você fará referência ao filme Peixe Grande, } \\
\text { de Tim Burton. }\end{array}$ \\
\hline $\begin{array}{l}\text { Resumo } \\
\text { Filme }\end{array}$ & $\begin{array}{l}\text { Você é um colunista social e semanalmente (às sextas-feiras) escreve } \\
\text { uma página para o Jornal Notícias da Hora. Entre notas sociais de } \\
\text { festas, eventos e até fofocas, você dá dicas de filmes. O filme Big } \\
\text { Fish, de Tim Burton, estreará na próxima semana e você aproveita a } \\
\text { oportunidade para escrever um resumo do filme atraindo o público } \\
\text { para a audiência. }\end{array}$ \\
\hline $\begin{array}{l}\text { Resenha De } \\
\text { Filme ou } \\
\text { Resenha } \\
\text { Cinematográfica }\end{array}$ & $\begin{array}{l}\text { Você é um crítico de cinema que escreve para a Revista Evidência de } \\
\text { circulação semanal e nacional. O filme Big Fish, de Tim Burton, } \\
\text { estreou na semana anterior e você aproveita para escrever uma } \\
\text { resenha do filme destacando a excelência do enredo, que destaca, } \\
\text { entre outros temas, a relação pais e filhos. }\end{array}$ \\
\hline Conto & $\begin{array}{l}\text { Você é apaixonado pela literatura regional. Gosta de ouvir causos e } \\
\text { contos populares. Cresceu em uma cidade interiorana cuja diversão } \\
\text { era a reunião dos moradores no coreto central para contação de } \\
\text { histórias e roda de viola. O município lançou um concurso de causos e } \\
\text { contos. Você não hesitou em fazer sua inscrição e, para concorrer, } \\
\text { preparou um conto de seu encontro com um gigante faminto que } \\
\text { aterrorizava a cidade, mas que você conquistou e dele se tornou } \\
\text { grande amigo. }\end{array}$ \\
\hline Reportagem & $\begin{array}{l}\text { Você é um repórter freelancer e tem dedicado suas atividades à } \\
\text { cobertura de eventos culturais. Sabendo da estreia do filme Big Fish, } \\
\text { você foi assistir a ele e aproveitou para entrevistar algumas pessoas } \\
\text { na saída do cinema. Daí surgiu uma reportagem que você pretende } \\
\text { vender para um jornal local. }\end{array}$ \\
\hline Notícia & $\begin{array}{l}\text { Na noite de sábado estreou o filme Big Fish. O sucesso foi tão grande } \\
\text { que houve engarrafamento na porta do cinema. Dois motoristas, } \\
\text { insatisfeitos com o tumulto, acabaram trocando insultos e foram às }\end{array}$ \\
\hline
\end{tabular}




\begin{tabular}{|l|l|}
\hline Memória & $\begin{array}{l}\text { vias de fato. O fato acabou na delegacia local. Você, um contundente } \\
\text { repórter policial, que escreve para o Jornal Denúncia, aproveitou e } \\
\text { publicou tudo. }\end{array}$ \\
\hline $\begin{array}{l}\text { Você é uma doce avó que ama contar histórias para os netos. Certo } \\
\text { dia, um deles desobedeceu aos pais e levou umas palmadas. Pela sua } \\
\text { doçura, correu para seus braços, buscando aconchego. Você, } \\
\text { entretanto, sem perder a amabilidade decidiu contar-lhe uma história } \\
\text { de suas travessuras, especialmente de uma que a deixou um mês sem } \\
\text { poder brincar porque teve graves ferimentos. É lógico que você não } \\
\text { vai deixar de dar um toque mágico à história como fazia a } \\
\text { personagem-pai do filme Big Fish. }\end{array}$ \\
\hline Poema & $\begin{array}{l}\text { Você é um poeta de uma cidade do interior, na qual há o Clube } \\
\text { Amante das Artes e das Letras que, mensalmente, se reúne para um } \\
\text { sarau. Devido às últimas notícias sobre os déficits na educação, } \\
\text { demonstrados pelos resultados das avaliações nacionais (SAEB, } \\
\text { Prova Brasil, Provinha Brasil), você escreveu um poema em louvor } \\
\text { aos tempos de outrora, especialmente no que diz respeito ao tempo } \\
\text { de dedicação dos pais na educação dos filhos, contando-lhes histórias } \\
\text { estimuladoras da imaginação, da reflexão crítica e promotoras da } \\
\text { interação social. Seu poema será recitado no próximo encontro do } \\
\text { Clube. }\end{array}$ \\
\hline
\end{tabular}

QUADRO 2: Contextos para produção

Percebeu-se que os professores ficaram "desorientados" com os contextos de produção. Uma professora, fazendo referência ao detalhamento do contexto de produção, argumentou: "Os alunos sabem fazer reportagem, porque todo ano a escola desenvolve um trabalho com jornal. Eles não precisam mais de tanta orientação." Se, por um lado, a professora parecia ter razão, pois, segundo ela mesma, a escola já realizava atividades com jornal anualmente, por outro, afloram as questões: Que atividades são realizadas? Que abordagem é dada à reportagem? São considerados os aspectos enunciativos do gênero? A repetição anual das atividades possibilita o aprimoramento das capacidades de linguagem? Há progresso no domínio do gênero?

Por outro lado, nem mesmo que as respostas às perguntas anteriores explicitassem que as atividades são variadas, que os professores utilizam diversos exemplares de textos do gênero em estudo para observação dos planos geral ${ }^{15}$ e global ${ }^{16}$ do texto, e enfatizam os

\footnotetext{
${ }^{15}$ Ao conjunto da infraestrutura textual, Bronckart (2007) denomina plano geral do texto. Diz o autor: "O plano geral refere-se à organização de conjunto do conteúdo temático; mostra-se visível no processo de leitura e pode ser codificado em um resumo" (BRONCKART, 2007, p. 120).

${ }^{16} \mathrm{O}$ plano textual global é reconhecido pela silhueta do texto, ou seja, pelos elementos paralinguísticos ou paratextuais, que correspondem às unidades semióticas não verbais, tais como, quadros, tabelas, imagens,
} 
aspectos enunciativos, em primeira instância, e, posteriormente, os aspectos estruturais da língua a serviço do gênero, facilitando ao aluno a apropriação dos elementos estáveis do gênero para uma produção consciente do texto, seria possível dispensar o contexto de produção já que, pelo menos, o objetivo e o tema de cada reportagem devem (deveriam) ser diferentes.

As dificuldades ${ }^{17}$ de realização da atividade e a fala da professora também revelam que o oferecimento de um contexto para produção não é uma prática desenvolvida pelos docentes e que persiste um processo ensino-aprendizagem no qual a tipologia textual é o foco do ensino da produção escrita em detrimento do trabalho com gêneros textuais. Como aponta Barbosa,

[...] diversas tipologias têm sido propostas ou importadas de teorias linguísticas. A maioria dessas tipologias está calcada em critérios estruturais/formais (narração, descrição, dissertação, etc.). Ora, baseadas só em aspectos estruturais e/ou funcionais, essas propostas ou deixam de capturar aspectos da ordem da enunciação ou do discurso, ou, quando consideram esses aspectos, fazem-no de maneira externa às classificações, Por isso, falham no que concerne à consideração de importantes elementos do processo de compreensão e produção de textos. (BARBOSA, 2002), p. 152)

Assim sendo, foi explicado ao grupo em formação que o contexto de produção norteia o trabalho de escrita, gerando mais segurança nos alunos. Psicologicamente, ocorre uma ativação de mecanismos sociocomunicativos, desenvolvendo-se a capacidade de ação, conforme demonstra a figura abaixo.

esquemas, e pelos elementos supratextuais, como formatação da página, emprego de título, subtítulo, paragrafação, destaques textuais, como negrito, itálico, sublinhados, entre outros, no caso de textos escritos. Em se tratando de textos orais, observam-se os silêncios, a manutenção ou alteração de tom, os prolongamentos silábicos etc.Analogamente, corresponde à construção composicional a que se refere Bakhtin (2003), quando conceitua gêneros discursivos.

${ }_{17}$ Tais dificuldades revelaram-se, particularmente, pela extensão de tempo para o cumprimento da tarefa e pela diversas vezes em que os grupos consultaram a professora ministrante a respeito do contexto recebido. 


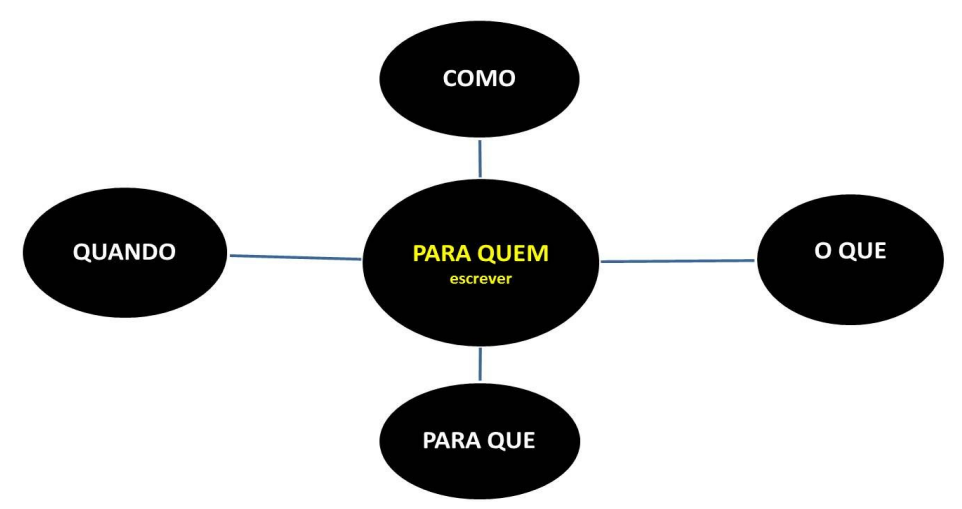

Figura 1: Mecanismos sociocomunicativos implicados na capacidade de ação

Para detalhamento da figura acima, foram retomados os contextos de produção dos gêneros sugeridos para a atividade de escrita (Cf. QUADRO 2) e os professores foram "respondendo" a cada mecanismo sociocomunicativo. Ao final, os textos produzidos foram socializados no grupo e, após a leitura de cada texto, algumas observações para destacar os elementos estáveis do gênero foram realizadas, numa espécie de bilhete orientador oral dos textos e/ou de sugestão de melhorias.

Em se tratando dos tipos de discurso e das sequências tipológicas (BRONCKART, 2007), os professores reconheceram-nos, associando às ações de linguagem do agenteprodutor. Ficou claro que o uso de uma sequência acontece pelo projeto de dizer dos enunciadores e pelas representações sociais que fazem de seus interlocutores. Uma professora ratificou o que tinha sido dito na aula anterior: "o importante é que o aluno reconheça o jogo de linguagem na produção do texto e saiba mover-se nesse jogo de forma interativa e alcance seu interlocutor".

Uma das atividades desenvolvidas quando se tratava das sequências tipológicas foi juntar os parágrafos da crônica "Ser brotinho", de Paulo Mendes Campos. A crônica não tem necessariamente uma ordem nos parágrafos. Não foram aplicados elementos articuladores, o que possibilitava a hierarquização do texto em diversas formas. Essa atividade orientou o olhar dos professores para a modelização do gênero. O objetivo não era construir um modelo didático do gênero crônica, mas ao longo das discussões, foram recuperados alguns de seus elementos estáveis e discutido o que é o modelo didático e finalizadas as considerações sobre sequências tipológicas.

Para avaliar o entendimento dos professores quanto à distinção entre gêneros textuais e tipologia textual, ou seja, sequências tipológicas, a quinta pergunta da avaliação 
solicitava o registro dessa diferença. Apenas três professores não produziram respostas satisfatórias. Os demais revelaram ter compreendido que um gênero textual pode ser composto por várias sequências tipológicas. A categoria mais comum foi "partes" do texto, isto é, um gênero é composto por diferentes "partes", ou seja, diferentes sequências.

No que concerne à construção colaborativa e coletiva do modelo didático do gênero artigo de opinião, tal atividade não trouxe confusão aos professores. Eles reconheceram bem cada capacidade e seus elementos. Entretanto, o fato de entenderem que deveriam construir o modelo didático com seus alunos causou certo burburinho, visto que estes não entenderiam termos como capacidade de ação, capacidade discursiva, capacidade linguísticodiscursiva, sequências tipológicas etc. Com muito diálogo, o equívoco foi resolvido. Foi enfatizada a importância da teoria para o professor e que os termos específicos e mais complexos desta abordagem teórico-metodológica de gêneros textuais não precisam ser apresentados aos alunos.

Outrossim, observa-se que, em processos de mediação formativa, executar matrizes de atividades (ou atividades-piloto) podem contribuir para que haja uma conscientização de práticas a serem realizadas (ou já realizadas, porém, de forma não consciente) na recontextualização de conhecimentos. Conforme Barros (2012), os professores precisam tomar consciência de que a transposição de conhecimentos científicos para o contexto didático exige trabalho sistematizado e consciente, ou seja, é preciso que o "como" fazer seja também reconhecido para ser colocado em prática. Isso não significa que o que se realiza em uma formação continuada tenha de ser repetido em sala de aula - não se trata de "receita", mas atividades práticas nos cursos oferecidos aos professores também promovem a reflexão sobre o fazer pedagógico.

No encontro destinado à modelização dos gêneros selecionados individualmente pelos professores ${ }^{18}$, uma contradição evidenciou-se em relação à construção do modelo didático do gênero artigo de opinião. O encontro chegou ao fim e quase nenhum docente realizou a atividade, ainda que a formadora tenha se empenhado em atender a todos tirando as dúvidas. Alguns professores reclamaram da aula e disseram que continuavam

\footnotetext{
${ }_{18}$ Para este encontro, antecipadamente, a professora ministrante fez uma seleção de artigos científicos a respeito de diversos gêneros textuais, deixando-os disponíveis nos computadores da sala do curso a fim de facilitar a pesquisa. Alguns artigos eram mais teóricos; outros, relatos/análise de prática realizadas com gêneros textuais. Além dos artigos, algumas SD foram apresentadas aos professores, em versão impressa ou digital.
} 
confusos diante da construção do modelo didático e da SD. As reclamações diziam respeito à identificação dos elementos estáveis no texto e a sua correlação às capacidades de linguagem, isto é, disseram que não conseguiam determinar se dado elemento estável pertencia à capacidade de ação, discursiva ou linguístico-discursiva.

Nesse sentido, os professores foram alertados sobre certa dificuldade quanto aos termos da teoria, os quais foram novamente explicados, mas que o trabalho não é difícil. Foram lembrados de que há etapas a serem seguidas e adiantá-las ou não realizá-las geram dificuldades ${ }^{19}$. Insistiu-se, portanto, na necessidade de leitura dos exemplares dos gêneros para observação de seus elementos estáveis.

Os episódios desses encontros direcionam para a dificuldade de apropriação da modelização dos gêneros e planificação da SD. Entende-se que os problemas podem advir da "contemporaneidade" do ISD, assim como podem ser reflexo também de certa comodidade que os três níveis de concretização da transposição didática "oferecem" ao professor, já que "prescrevem" a prática pedagógica pela determinação dos conteúdos, como demonstra o seguinte fragmento de diálogo entre os professores durante a formação.

$[\ldots]$

PP- A pergunta que eu fiz [...] foi: Quais foram as dificuldades que vocês encontraram nessas duas semanas que nós nos ausentamos para a construção da SD? Quais foram?

$\mathrm{C}_{1^{20}}-\mathrm{Na}$ sequência, né?

PP-É.

C1 - O modelo, beleza, é fácil até! Mas a sequência dá trabalho pelo seguinte, porque nós temos que construir todo ele, né. Tem que formar todo o conteúdo em cima de todo o gênero que eu vou trabalhar. E aí, mesmo eu tendo esse meu modelo aqui, que eu sei que, por exemplo, tem adjetivo lá na capacidade linguístico-discursiva, tem adjetivo, tem o pronome... Mas como eu trabalhar de repente aqui dentro do texto? Às vezes, a dificuldade é que nem sempre vou encontrar dentro do texto que eu escolhi. Então a gente tem de tomar muito cuidado com isso.

$\mathrm{C}_{2}$ - Eu não entendi esse final [...] O que você não vai encontrar dentro do texto?

$C_{1}$ - Por exemplo, eu escolhi os textos do gênero que eu quero trabalhar, que é o gênero lenda, por exemplo. [...] E assim... no primeiro exercício que eu resolvi eu achei que eu já tinha colocado um monte de coisa que o aluno precisava conhecer, que não precisava de mais nada. Nossa, aqui já tá tudo! Aí eu passei depois pra outro conteúdo. Aí, quando a [nome] corrigiu, o que ela explicou pra mim: que ainda era pouco, que ainda tem de acrescentar muito mais exercícios. E a dificuldade é eu elaborar o exercício, pra não ficar repetitivo, de repente um exercício muito parecido com o outro, e também trabalhar as capacidades linguísticas, que, eu acho, dependendo do texto é um pouco difícil.

C2 - Essa coisa de e-la-bo-rar...

C1-E-la-bo-rar...

C2 - Porque a gente está acostumado a pegar tudo no livro...

\footnotetext{
${ }^{19}$ Alguns professores estavam construindo o modelo didático sem a leitura de exemplares do gênero (alguns sequer tinham levado os textos). Prevendo a falta de textos, foi preparada uma caixa com vários textos em diversos gêneros.

${ }^{20}$ Para preservar a identidade dos professores que participaram da formação, seus nomes foram substituídos pela letra C (referência a Cursista) e o número que segue indica a ordem de "entrada" no diálogo.
}

Eutomia, Recife, 15 (1): 358-383, Jul. 2015 
C1 - Porque, na verdade, eu estou elaborando... A gente pega pronto dos livros, né.

[...]

(áudio gravado em 25.05.2011).

As duas sequências finais desse diálogo demonstram que a seleção dos objetos de ensino da língua portuguesa é determinada, particularmente, pelo livro didático, o que foi comprovado na primeira avaliação do curso, quando foram questionados sobre como escolhiam um gênero a ser ensinado. As respostas válidas ${ }^{21}$ mesclaram vários critérios, ou seja, um mesmo professor apontou várias situações de escolha. Entre elas destacaram-se: a adequação a documentos prescritores do ensino (Projeto Político Pedagógico, Referencial Curricular da Rede Estadual de Ensino e o próprio livro didático), o aluno - sua idade, sua realidade (cultura), suas necessidades (preparar-se para o vestibular, por exemplo) - e o próprio professor (sua afinidade/domínio do gênero).

Apesar de no trecho de diálogo transcrito anteriormente e na primeira avaliação já ter ficado clara a forma de seleção dos gêneros, na segunda avaliação do curso, na questão $n^{\circ} 2$, insistiu-se nessa investigação, com o objetivo de verificar a apropriação dos fundamentos básicos quanto à necessidade de um ensino contextual dos gêneros, ou seja, objetivava-se perceber se, depois de orientados teórica e metodologicamente, os professores consideraram as práticas sociais e as práticas de linguagem em que os alunos estavam inseridos.

Nove professores responderam ao questionário; e as respostas demonstram que, pelo menos parcialmente, não houve apropriação teórico-prática dos conteúdos trabalhados durante a formação, no que concerne à escolha dos objetos de ensino. Persistem os critérios "tradicionais", como demonstra o QUADRO 4. De outra forma, como afirmam Dolz, Schneuwly e Haller (2004), a seleção de um gênero, por conseguinte sua modelização, repousa sobre três princípios interdependentes e em evolução constante: a legitimidade, a pertinência e a solidarização.

A legitimidade diz respeito aos saberes teóricos ou elaborados pelos especialistas. Os primeiros são materializados em documentos que norteiam o fazer pedagógico, como os Referenciais de Ensino e até o livro didático, e os segundos são observados em textos de enunciadores legitimados como "autoridade" no gênero. A pertinência está relacionada às

\footnotetext{
${ }^{21}$ Seis respostas estão vagamente formuladas e não permitem o entendimento de como o professor seleciona este ou aquele gênero para ensinar.
} 
capacidades dos alunos, às finalidades e objetivos do processo ensino-aprendizagem e podem ser identificados nos Projetos Políticos Pedagógicos e nos Projetos de Ensino. A solidarização concerne à efetivação de um novo saber. Em se tratando da formação de professores, esses três princípios circundam a articulação e a transformação do conhecimento científico em conhecimento a ser ensinado.

No QUADRO 4, as respostas dos professores comprovam a circunscrição desses três princípios (legitimidade, pertinência e solidarização) na seleção dos saberes a serem didatizados. Apesar de interdependentes, é possível dizer que as respostas que apontam para o livro didático e/ou referencial curricular são justificadas pelo princípio da legitimidade; a segunda e a terceira respostas fundam-se no princípio da pertinência.

\begin{tabular}{|c|c|c|}
\hline $\begin{array}{l}\text { Categoria de } \\
\text { escolha }\end{array}$ & $\begin{array}{l}\text { Fragmentos de algumas } \\
\text { respostas }\end{array}$ & Análise \\
\hline $\begin{array}{c}\text { Livro Didático } \\
\text { ou Referencial } \\
\text { Curricular } \\
\text { (07) }\end{array}$ & $\begin{array}{l}\text { "porque o livro didático trazia } \\
\text { algumas sugestões" }\left(\mathrm{P}_{41}\right) \text {; } \\
\text { "a escolha se deu por ser } \\
\text { conteúdo presente no livro } \\
\text { didático, por constar no } \\
\text { referencial e [...] um gênero } \\
\text { agradável de ler e produzir" }\left(\mathrm{P}_{26} 6\right) ; \\
\text { "além de fazer parte da ementa } \\
\text { para a série, oferecia mais } \\
\text { facilidade e atrativos para o } \\
\text { desenvolvimento da sequência" } \\
\text { (Po3); } \\
\text { "por julgar ser bem relevante, em } \\
\text { suas características, ao } \\
\text { desenvolvimento das capacidades } \\
\text { textuais dos alunos do } 9^{\circ} \text { ano" } \\
\text { (Po6). }\end{array}$ & $\begin{array}{l}\text { Na maioria das respostas está } \\
\text { explícito que a seleção foi } \\
\text { realizada com base em critérios } \\
\text { "legítimos"; em outras, } \\
\text { especialmente, no questionário } \\
\text { Po6, não está explícito, todavia, } \\
\text { entende-se que, se foram } \\
\text { observadas as capacidades } \\
\text { necessárias, é no Referencial } \\
\text { Curricular que se apoiou, posto } \\
\text { que, nesse documento, } \\
\text { encontram-se as competências e } \\
\text { habilidades de cada série/ano. }\end{array}$ \\
\hline $\begin{array}{l}\text { Tema do } \\
\text { gênero } \\
\text { (01) }\end{array}$ & $\begin{array}{l}\text { "Por tratar do comportamento } \\
\text { humano" (Po2) }\end{array}$ & $\begin{array}{l}\text { Esta resposta } \\
\text { subentender a busca por umite } \\
\text { prática } \\
\text { promotora de contextualizada, } \\
\text { "múltiplos, dêiticos, ideológicos, } \\
\text { culturais e críticos"2. (OLIVEIRA, }\end{array}$ \\
\hline
\end{tabular}

\footnotetext{
${ }^{22}$ Nessa perspectiva, embora o gênero textual/texto continue sendo unidade e objeto de ensino, o ensino da língua alcança patamares para além dos linguístico-enunciativos. Contribui para a formação de sujeitos agentes na sociedade e que, competente e conscientemente, utilizam os gêneros textuais como instrumento de interação e de concretização de objetivos diversos ideologicamente estabelecidos. Assim, entende-se a existência de letramentos (vários), pois há uma adequação a situações sociocomunicativas (BARROS, 2012, 2009).
} 


\begin{tabular}{|c|c|c|}
\hline & & $\begin{array}{l}\text { 2009, apud BARROS 2012). } \\
\text { Portanto, se funda nos princípios } \\
\text { da pertinência e da solidarização, } \\
\text { visto que objetiva a solidificação } \\
\text { de saberes já adquiridos e/ou de } \\
\text { novos saberes. }\end{array}$ \\
\hline $\begin{array}{c}\text { Ensino em } \\
\text { espiral } \\
\text { (01) }\end{array}$ & $\begin{array}{l}\text { "havia trabalhado em anos } \\
\text { anteriores" }\left(P_{15}\right)\end{array}$ & $\begin{array}{l}\text { Novamente evidencia-se o } \\
\text { princípio da legitimidade. Poder- } \\
\text { se-ia dizer que esta resposta está } \\
\text { em perfeito acordo com as } \\
\text { proposições teórico- } \\
\text { metodológicas do ISD; porém, há } \\
\text { um questionamento latente: Os } \\
\text { professores têm consciência do } \\
\text { ensino em espiral, ou eles } \\
\text { repetem "planejamentos e ações" } \\
\text { que foram exitosas em anos } \\
\text { anteriores? }\end{array}$ \\
\hline
\end{tabular}

QUADRO 4: Critérios de seleção dos gêneros didatizados

Se por um lado a maioria dos professores continuou adotando o princípio da legitimidade, um professor associou esse princípio ao da pertinência, conforme registrado no seguinte fragmento do diálogo:

[...]

PP - Nós vamos conversar mais ainda sobre tudo isso ao longo das apresentações. Alguém quer dizer assim, eu quero ser o primeiro a apresentar? [...]

$\mathrm{PP}$ - O [nome]. Então vem [nome].

C6 - Eu posso ser o primeiro, quanto mais cedo, melhor...

$[\ldots]$

C6 - [...]No caso eu vou trabalhar o conto psicológico, aí eu perguntei: por que esse gênero? Por quê?

C5 - Nossa! Que difícil!...

$\mathrm{C}_{4}$ - Então, é mesmo. Por quê? Vai, pode explicar...

C6 - Há explicação.

C4-Tá!

C6 - Eu trabalho numa escola indígena e esse povo tem como cultura o contar história. E nessas histórias, eles contam contos, (ininteligível), lendas Sendo assim eu decidi trabalhar o conto psicológico porque os alunos gostam de contar suas histórias e seria bom tê-las registradas. Como é que funciona a cultura indígena. Eles gostam muito, mas muito, muito mesmo de contar histórias. E quando eles contam histórias é como se eles tivessem vivendo aquilo. Se eles vão contar uma lenda de milhões anos atrás, de milhares de anos atrás, é como se ele tivesse vivendo. Então aí que eu percebi que a gente poderia trabalhar com eles, porque o conto psicológico, umas das características dele é trabalhar o sentimento da pessoa. Eles vivem aquilo como se fosse a realidade. E o outro motivo que eu não coloquei aqui é que o livro didático da minha escola [...] a primeira seção, não sei, ela traz algumas coisas e já tem vários exercícios nessa linha. Então, olha só, eu já vou pegar as duas coisas e trabalhar, né...

C5- Os exercícios da...

C6- É assim... Na primeira unidade, se eu não me engano, tem dois textos desse gênero e vários exercícios explicando, o que é, por que, para que e um monte de coisa, né. 
$\mathrm{C}_{4}$ - Você já começou a aplicar com eles ou não?

C6 - Pior que já.

$\mathrm{C}_{4}$ - Só de curiosidade: você sentiu algum interesse?

C6 - [...] num ponto não, (ininteligível), mas por outro lado, o negócio tá lá em cima, mas como a minha referência vai ser o nono ano, eu acho que vai ter mais preparação...

$\mathrm{C}_{4}$ - porque quando eu li pros meus alunos esses contos psicológicos, eles odiaram... Professora, esse povo é doido... Por isso eu acho que se eu fosse fazer...

C6 - Bom vamos lá! [...] então eu escolhi alguns para eu seguir como base para eu tirar as coisas. Restos do carnaval, que está lá no livro, Felicidade Clandestina, da Clarice Lispector, Eu estava ali deitado, que também está no livro, esse é um dos que os meninos gostaram...

$\mathrm{C}_{2}$ - Clarice não pode faltar, né...

C6 - Cem anos de perdão, também da Clarice Lispector, Natal na barca, e tem mais um outro que eu não coloquei aqui, mas, sei lá, são vários. Além desses daqui, eu peguei mais um monte pra tirar as coisas. Segundo o que eu estudei pelos contos, os elementos fixos que estavam presentes em todos eles. Ele trabalha com as lembranças dos personagens. O conto psicológico é isso: é trabalhar essas lembranças É narrado em primeira pessoa, ou seja, o narrador é personagem em todos eles. É um narrar fictício; é... todos nós sabemos o que é. O tempo de um conto psicológico. No conto, o tempo é psicológico, ou seja, ele não segue aquela linha...

C5 - Temporal...

C6 - passado, presente e futuro. Ele fica oscilando... ele vai e volta, vai e volta...

$\mathrm{C}_{5}$ - quer dizer, tem muitos flashes...

C6 - Isso é muito comum na tribo Kaiowá. Quando o povo Kaiowá vai contar uma história pra você, você não entende nada...

C1 - Nada...

C6 - porque eles ficam indo e voltando, indo e voltando, indo e voltando. Aquilo, se você não está acostumado a lidar com eles, você não entende a história...

C1 - É. Você não entende...

C6 - então eu achei muito oportuno trabalhar isso com eles, porque é da cultura deles esse narrar da produção psicológica.

$[\ldots]$

(áudio gravado em 25.05.2011).

Percebe-se que o professor representado no diálogo pela sigla C6 observou aspectos pertinentes ao contexto sociocultural dos alunos, associando-os ao gênero conto psicológico. Essa associação ratifica a própria noção de gênero de texto.

A noção de gênero permite incorporar elementos da ordem do social e do histórico (que aparecem na própria definição da noção); permite considerar a situação de produção de um dado discurso (quem fala, para quem, lugares sociais dos interlocutores, posicionamentos ideológicos, em que situação, em que momento histórico, em que veículo, com que objetivo, finalidade ou intenção, em que registro, etc.); abrange o conteúdo temático - o que pode ser dizível em um dado gênero, a construção composicional - sua forma de dizer, sua organização geral que não é inventada a cada vez que nos comunicamos, mas que está disponível em circulação social - e seu estilo verbal - seleção de recursos disponibilizados pela língua, orientada pela posição enunciativa do produtor do texto. Neste sentido, a apropriação de um determinado gênero passa, necessariamente, pela vinculação deste com seu contexto sócio-histórico-cultural de circulação. (BARBOSA, 2002, p. 152-153). 
No contexto apresentado pelo C6, o conteúdo temático e a construção composicional do gênero conto psicológico recuperam elementos discursivos da cultura indígena. Por isso, é possível afirmar que a seleção do gênero foi adequada para o contexto sociocomunicativo em que os alunos estão inseridos, porquanto "é necessário escolher gêneros representativos das grandes famílias de gêneros em uso em uma determinada comunidade verbal." (BRONCKART, 2010, p. 171).

No que concerne ao instrumento utilizado para a revisão do texto, investigou-se que instrumentos os professores utilizam para a correção dos textos. Três respostas foram vagas e não possibilitaram uma categorização das inferências feitas nos textos dos alunos. Três educadores disseram indicar (com flechas, com grifos) os desvios da norma culta. Outros quatro disseram estabelecer critérios de avaliação, parecendo condizer com a proposta do ISD. Todavia, o desenvolvimento da resposta possibilita o entendimento de que esses critérios são de observação das capacidades linguístico-discursivas e não das capacidades de ação e/ou discursivas. Dois disseram fazer comentários no final do texto dos alunos, permitindo entender que utilizam a correção interativa. ${ }^{23}$ (RUIZ, 2001; NIÉRI, 2010). Ao longo da formação, foi-lhes apresentada a lista de controle. Alguns cursistas comentaram que esse instrumento facilitaria a correção do texto, e que, no contexto escolar, os alunos saberiam que critérios deveriam ser observados no texto e poderiam se autoavaliar. Para comprovar essa hipótese, na avaliação final do curso, novamente questionou-se sobre o instrumento regulador dos textos. As respostas delinearam a seguinte situação:

- quatro professores não utilizaram a lista de controle, mas afirmaram desenvolver a correção interativa, representada pela seguinte resposta: "as interferências nos textos dos alunos foram com conversas no texto (na folha), com sugestões, com perguntas, com orientações e reescritas" (P15);

- três professores fizeram uso da lista de controle, sendo que dois avaliaram positivamente esse mecanismo ("ficou muito mais fácil de corrigir") (P47) e uma não opinou, porque, no encontro final, ainda não tinha terminado a correção dos textos;

\footnotetext{
${ }^{23}$ A correção interativa é materializada por comentários às margens dos textos dos alunos e/ou "bilhetes" deixados pelo professor no final do texto sobre as características do gênero e servem para orientar a reescrita.
} 
- um professor utilizou a lista de controle e a avaliou de forma negativa: "Sim, mas deu muito trabalho e alguns alunos não gostaram de saber que não tinham atingido o objetivo. (Dois alunos rasgaram seus textos, ao lerem as observações). Foi feito um cartaz e afixado na sala com os elementos estáveis do gênero." (P41)

A última situação delineada provoca o surgimento de algumas questões: as causas dos alunos terem rasgado os textos residem na lista de controle ou no fato de eles não terem se adequado ao gênero? O gênero selecionado fazia sentido para sua realidade? Contextos exteriores ${ }^{24}$ ao gênero, por exemplo, de bilinguismo ou multilinguismo, afetam os resultados do trabalho com gêneros textuais e SD? Tais respostas demandam investigações peculiares e divergentes às realizadas, embora entrecruzadas à formação de professores.

Prosseguindo a investigação a respeito do ISD e sua "adequação" à prática pedagógico na sétima questão da primeira avaliação do curso perguntou-se: "Que dificuldades você observa na didatização do ISD25?" Todas as respostas apontaram para a construção do modelo didático e da SD, justificando-a pela falta de tempo, pela dificuldade de trabalhar a gramática no texto (a gramática funcional), pela imperícia em construir as atividades da SD, pela falta de material ou recursos para a reprodução da SD. Neste caso, um professor questionou: "Como; passar na lousa? Ou tirar xerox?" (P31).

Na segunda avaliação, a questão oito solicitava um relato do desenvolvimento da SD e que fossem destacados aspectos positivos e negativos. Pelas respostas, transcritas no QUADRO 5, é perceptível que os aspectos positivos direcionam para uma prática pedagógica dinâmica, contextualizada e que "agrada" os alunos, visto que se aproxima da realidade deles e facilita o processo de escrita. Quanto aos aspectos negativos, estão direcionados a problemas do sistema educacional e a fatores extraeducacionais, mas não à engenharia da didática das línguas, ao gênero e/ou SD em si.

\footnotetext{
${ }^{24}$ No cruzamento dos dados gerados pela pesquisa, identificou-se que a resposta dada veio de um professor que trabalha em uma escola indígena. Nesse contexto, questiona-se: Quais as contribuições e os efeitos do trabalho com gêneros textuais e SD em situações de bilinguismo, na qual a língua portuguesa é (quase) a segunda língua?

${ }^{25}$ A procura de evitar repetições, utilizamos a expressão "didatização do ISD", todavia cabe esclarecer que não fazemos a transposição do ISD, mas dos gêneros textuais. Tampouco se trata de aplicacionismo de uma teoria, mas de desenvolvimento de práticas de ensino-aprendizagem fundamentadas na teoria sociointeracionista discursiva.
} 


\begin{tabular}{|c|c|c|}
\hline Questionário & Aspectos positivos & Aspectos negativos \\
\hline Po2 & $\begin{array}{l}\text { "Foi produtivo na questão do } \\
\text { desenvolvimento da produção escrita } \\
\text { como também na linguagem oral, sendo } \\
\text { perceptível o gosto dos alunos em ler } \\
\text { fábulas, por serem textos curtos e assim } \\
\text { leram vários." }\end{array}$ & $\begin{array}{l}\text { "A maior dificuldade dos alunos foi a de } \\
\text { organizarem as ideias e escrevem os } \\
\text { textos com coesão." }\end{array}$ \\
\hline Po3 & $\begin{array}{l}\text { "A sequência foi realizada muito } \\
\text { tranquilamente, porque o gênero } \\
\text { escolhido agradou aos alunos, despertou } \\
\text { seu interesse, fazendo com que eles } \\
\text { 'respondessem bem' aos meus anseios." }\end{array}$ & $\begin{array}{l}\text { "Apenas algumas questões 'fugiram' do } \\
\text { planejado, como a demora na execução de } \\
\text { algumas atividades. Interrupções do } \\
\text { processo de ensino por fatores externos à } \\
\text { sala de aula (da escola) e, como é comum, } \\
\text { um ou outro caso isolado de aluno um } \\
\text { pouco relapso na execução de sua } \\
\text { atividade." }\end{array}$ \\
\hline Po6 & $\begin{array}{l}\text { "O ponto positivo é o fato de, conhecendo } \\
\text { nossos alunos em suas particularidades, } \\
\text { podemos aproximar o conteúdo deles com } \\
\text { atividades mais pertinentes." }\end{array}$ & $\begin{array}{l}\text { "Quanto à recepção dos alunos variou de } \\
\text { positiva a negativa, durante o processo, } \\
\text { posto que julgaram cansativo o processo } \\
\text { de aplicação da sequência." }\end{array}$ \\
\hline P14 & $\begin{array}{l}\text { "Pela minha mudança de gênero, creio que } \\
\text { não apliquei, não fiz uma sequência como } \\
\text { se deve, mesmo assim consegui fugir } \\
\text { bastante da forma tradicional." }\end{array}$ & \\
\hline$P_{15}$ & $\begin{array}{l}\text { "Os alunos produziram os textos a partir } \\
\text { de uma orientação [...] Os alunos } \\
\text { produziram e através das rodas de leitura } \\
\text { foi possível perceber o crescimento de } \\
\text { cada um até o texto final." }\end{array}$ & $\begin{array}{l}\text { "A maior dificuldade foi conhecer o gênero } \\
\text { e desenvolver as atividades que levassem o } \\
\text { aluno a compreensão concreta do texto." }\end{array}$ \\
\hline$P_{41}$ & $\begin{array}{l}\text { "O bom é que os alunos gostaram da ideia } \\
\text { de publicarem um livro." }\end{array}$ & $\begin{array}{l}\text { "Por trabalhar em um escola rural, houve } \\
\text { muitos obstáculos. Muitas faltas por parte } \\
\text { dos alunos devido à chuva e ao frio; } \\
\text { repetição da mesma oficina para alcançar } \\
\text { o maior número possível de alunos; alguns } \\
\text { assuntos não foram bem aceitos pelos } \\
\text { alunos; outros foram bem feitos e houve } \\
\text { grande participação." }\end{array}$ \\
\hline P47 & $\begin{array}{l}\text { "O primeiro passo da SD foi a produção de } \\
\text { um texto. Verifiquei que os alunos já } \\
\text { possuem um conhecimento prévio do } \\
\text { gênero aplicado. As marcas encontradas } \\
\text { nos textos foram marcantes, o era uma } \\
\text { vez; em um lugar distante; um rei; uma } \\
\text { princesa; viveram felizes para sempre..." }\end{array}$ & \\
\hline
\end{tabular}

QUADRO 5: Aspectos positivos e negativos no processo de transposição didática interna 
Entende-se por tudo isso que, na realidade, os professores-cursistas, de um modo geral, não aderiam adequadamente ao trabalho com gêneros textuais em sua prática pedagógica, mesmo que essa proposta já exista há quase duas décadas, tomando os PCN como discussão inaugural. E o principal fator dessa não adesão, entre outros, pode ser a falta de ou a ineficácia na abordagem dos fundamentos teórico-metodológicos do ISD no processo de formação de professores.

\section{Considerações finais}

Nesta pesquisa, defendem-se pressupostos teórico-metodológicos fundamentados no ISD (sobretudo em sua vertente didática) para a realização de ações pedagógicas de formação inicial e continuada de professores. Como avalia um dos professores-cursistas,

trabalhar com sequência didática é ótimo, porque, assim, ela direciona o trabalho do professor, né. Só que a dificuldade do professor iniciante é que ele não tem aquela segurança, né. E como é uma metodologia nova, então assim falta suporte na graduação pra que você possa ter um suporte na graduação para depois, quando você for por isso na escola, nas suas aulas, você já ter um conhecimento prévio. E outro ponto assim que eu acho assim que alguns professores assim eles enfrentam uma certa dificuldade, porque se o professor, se ele já está acostumado com aquela metodologia e um professor já está com uns 20 ou 25 anos, é difícil ele mudar sua metodologia pra trabalhar com a SD. (áudio gravado em: 11.05.2011)

É certo que a realização de atividades, diga-se, piloto, ou matrizes, pode provocar dúvidas, anseios, sentimentos de incapacidade, resolvidos pelo diálogo, pela mediação formativa, e pelo uso de referenciais teóricos e de textos do próprio gênero em modelização. Por tudo isso, como aponta Cristovão, é possível afirmar que a abordagem didática do ISD "viabiliza a adoção de material didático voltado para atingir objetivos e desenvolver competências ao invés de atividades que garantam o simples cumprimento de conteúdo" (CRISTOVÃO, 2005, p. 160). E o trabalho mediado e cooperativo pode reverter o quadro educacional de ensino tradicional, fundamentado em aspectos estruturais da língua e do texto, ou seja, no ensino da gramática e dos tipos de texto.

O processo colaborativo instaurado durante a pesquisa contribuiu para a transposição didática externa, em primeiro nível (MACHADO; CRISTOVÃO, 2006), ou seja, avalia-se que os professores foram capazes de transformar o conhecimento científico em 
conhecimento a ser ensinado sobretudo no processo de construção do Modelo Didático de Gêneros em relação aos seus princípios constitutivos: legitimidade, pertinência e solidarização e na planificação das SD, ainda que não seja possível inferir que eles continuam aplicando tais conhecimentos em sua prática. Novas investigações, talvez, com o mesmo grupo de professores fossem necessárias.

Outro ponto a ser destacado foi a reorganização das práticas pedagógicas e a própria formação continuada dos professores. Uma fala significativa nesse sentido foi: "As vantagens é que assim temos uma forma organizada de trabalhar um gênero. O que achei mais interessante, nesse tipo de trabalho, é que também o professor estuda o gênero, não só o aluno." (P49). Em outras palavras, mediações formativas (ou pesquisas colaborativas) promovem o letramento do próprio professor, visto que reúne teoria e prática.

Por fim, a didatização do ISD e seus desmembramentos, desenvolvida por meio de trabalho colaborativo (construção de MD e de SD), rompe com o isolamento do professor, por conseguinte estabelece um novo norte para o processo ensino-aprendizagem da língua/linguagem e promove o desenvolvimento do agir docente. Rompe com o isolamento na medida em que a formação continuada colaborativa favorece a troca de conhecimentos entre formadores e professores cursistas e todos entre si, promovendo o processo de autoavaliação e autorreflexão.

\section{Referências bibliográficas}

BARBOSA, J. P. Do professor suposto pelos PCNs ao professor real de língua portuguesa: são os PCNs praticáveis? In: ROJO, R. (Org.). A prática de linguagem em sala de aula: praticando os PCNs. 2 ed. Campinas-SP: Mercado de Letras, pp. 149-182, 2002.

BARROS, E. M. D. de. Gestos de ensinar e de aprender gêneros textuais: a sequência didática como instrumento de mediação. Tese (Doutorado em Estudos da Linguagem). Universidade Estadual de Londrina, Centro de Letras e Ciências Humanas, Londrina/PR, 2012.

BRONCKART, J. P. Atividade de linguagem, texto e discursos: por um interacionismo sociodiscursivo. $2^{\mathrm{a}}$ edição. São Paulo: EDUC, 2007.

Gêneros de textos, tipos de discurso e sequências. Por uma renovação do ensino da produção escrita. Revista Letras, Santa Maria, v. 20, n. 40, pp. 163-176, jan/jun. 2010. 
CELANI, M. A. A. (Org). Professores e formadores em mudança: relato de um processo de reflexão e transformação da prática docente. 2. ed. Campinas-SP, Mercado de Letras, pp. 19-33, 2010 [2002].

CRISTOVÃO, V.L.L. Aprendendo a planificar o próprio trabalho: gêneros textuais na formação de professores de língua estrangeira. In: CRISTOVÃO, V. L. L.; NASCIMENTO, E. L. (Orgs.) Gêneros textuais: teoria e prática II. Palmas e União da Vitória-PR: Kaygangue, pp. $153-162,2005$.

A relação entre teoria e prática no desenvolvimento do professor. In: MAGALHÃES, M. C. C. A formação do professor como um profissional crítico: linguagem e reflexão. 2 ed. Campinas - SP: Mercado de Letras, pp. 179-198, 2009 [2004].

DOLZ, J.; NOVERRAZ, M.; SCHEUWLY, B. Sequências didáticas para o oral e escrita: apresentação de um procedimento. In: Gêneros orais e escritos na escola. Trad. e (Org). de Roxane Rojo e Glaís Sales Cordeiro. Campinas-SP: Mercado de Letras, pp. 95-128, 2004.

; SCHNEUWLY, B.; HALLER, Sylvie. O oral como texto: como construir um objeto de ensino. In: Gêneros orais e escritos na escola. Trad. e (Org). de Roxane Rojo e Glaís Sales Cordeiro. Campinas-SP: Mercado de Letras, pp. 149-185, 2004.

FREIRE, P. Pedagogia do Oprimido. 23 ed. São Paulo: Autores Associados: Cortez, 1987.

Pedagogia da autonomia: saberes necessários à prática educativa. Rio de Janeiro-RJ: Paz e Terra, 2002.

GIROUX, H. A. Os professores como intelectuais: rumo a uma pedagógica crítica da aprendizagem. Porto Alegre: Artes Médicas, 1997

KINCHELOE, J. L. A formação do professor como compromisso político: mapeando o pósmoderno. Trad. Nize Maria Campos Pellanda. Porto Alegre: Artes Médicas, 1997.

MACHADO, A.R.; CRISTOVÃO, V. L. L. A construção de modelos didáticos de gêneros: aportes e questionamentos para o ensino de gêneros. Linguagem em (Dis)curso, LemD, Tubarão/SC, v.6, n.3, pp.547-573, set./dez. 2006.

MAGALHÃES, M. C. C. A formação do professor como um profissional crítico: linguagem e reflexão. 2 ed. Campinas - SP: Mercado de Letras, 2009 [2004].

NIÉRI, J.S. A transposição didática do gênero dissertação escolar. Dissertação (Mestrado em Letras) - Faculdade de Comunicação, Artes e Letras, Universidade Federal da Grande Dourados, Dourados/MS, 2010.

OLIVEIRA, M. do S. Gêneros textuais e letramento. Disponível em: http://www.ucs.br/ucs/tplSiget/extensao/agenda/eventos/vsiget/portugues/Download\%20 \%20das\%2opalestras/Painel 14.08 Maria do Socorro.pdf. Acesso em: 10/04/2012. 
ROMERO, T. R. de S. Características linguísticas do processo reflexivo. In: MAGALHÃES, M. C. C. A formação do professor como um profissional crítico: linguagem e reflexão. 2 ed. Campinas - SP: Mercado de Letras, pp. 135-144, 2009.

RUIZ, E. Como se corrige redação na escola. Campinas: Mercado de Letras, 2001.

SCHNEUWLY. B. ;DOLZ, J. Gêneros orais e escritos na escola. Tradução e Organização de Roxane Rojo e Glaís Sales Cordeiro. Campinas: Mercado de Letras.

i Mariolinda Rosa Romera FERRAZ - Docente colaboradora da Universidade Federal da Grande Dourados.

E-mail: mariolindaferraz@gmail.com

ii Adair Vieira GONÇALVES - Professor Adjunto da Universidade Federal da Grande Dourados.

E-mail: adairgoncalves@uol.com.br

Recebido em 15/06/2015

Aceito em 20/07/2015 